\title{
Koloratzaile organikoz dopaturiko L-zeolita antena material luminiszente gisa
}

\author{
Luminescent antena material via the allocation \\ of organic fluorophores into zeolite L nanochanels
}

\author{
Leire Gartzia-Rivero*, David Martinez, Jorge Bañuelos
}

Kimika Fisikoa Saila, Zientzia eta Teknologia Fakultatea (UPV/EHU)

\begin{abstract}
LABURPENA: Zientzialariek askotan naturan bertan aurkitzen dute inspirazioa aurrerakuntza zientifikoak sustatzeko. Honen adibide nabaria da fotosintesian jarritako arreta berezia, eguzki-argia eraginkortasunez xurgatu eta energia kimikoan eraldatzeko gai den prozesu konplexua. Lan honen helburua fotosintesian gertatzen den oinarrizko prozesuetako bat imitatzea da, halaber, argiaren bilketaz arduratzen dena. Horretarako, eremu espektral zabalean argia xurgatzeko gai diren material fotoaktiboak garatu dira, zeinak argi gorria igortzeko berezitasuna izango baitute. Material lumineszente hauek garatzeko, koloratzaile organiko aproposak aukeratu dira L-zeolitaren nano-kanal unidimentsionaletan barneratzeko. Konfinamendu hau ezinbestekoa da energia trukea bultzatzeko, funtsezko prozesua energiaren garraioa eta eraldaketa ahalbidetzeko. Garatutako nanomaterialak aproposak dira argia tarte espektral zabalean eraginkortasunez biltzeko (antena jarrera) eta, ondoz ondoko energia trukeari esker, bereziki argi gorria igortzeko, hainbat arlo (bio)teknologikotan aplikagarria.
\end{abstract}

HITZ GAKOAK: koloratzaileak, zeolita, lumineszentzia, antena, energia-trukea, nanomateriala.

\begin{abstract}
Scientists often find in nature the inspiration to solve their problems and challenges. As a matter of fact, photosynthesis, where solar radiation is harvested efficiently and converted into chemical energy, is an appealing bioprocess. Therefore, in the herein reported work we intend to mimic a therein ongoing process, and develop materials which enable a broadband light absorption, whereas displays mainly red-edge emission. These luminescent materials were designed by means of the selection of suitable organic dyes and their subsequent allocation into unidimensional pores of L-type zeolite. Such confinement boosts the energy transfer, being this a key process for energy transport and conversion. As consequence, the herein customized nanomaterial allows efficient light harvesting over a wide spectral region (antenna behavior) and, thanks to the ongoing energy transfer, fluorescence at the red edge is mainly recorded, with potential applications in many (bio)technological areas.
\end{abstract}

KEYWORDS: dyes, zeolite, luminescence, antenna system, energy transfer, nanomaterial.

* Harremanetan jartzeko / Corresponding author: Leire Gartzia-Rivero, Molekulen Espektroskopia Taldea, Kimika Fisikoa Saila, Zientzia eta Teknologia Fakultatea (UPV/EHU), Sarriena auzoa, z/g, 48940 Leioa. Bizkaia, Euskal Herria. - leire. gartzia@ehu.eus - https://orcid.org/0000-0002-2240-4538.

Nola aipatu / How to cite: Gartzia-Rivero, Leire; Martinez, David; Bañuelos, Jorge (2019). "Koloratzaile organikoz dopaturiko L-zeolita antena material luminiszente gisa»; Ekaia, 35, 2019, 101-118. (https://doi.org/10.1387/ekaia.19659).

Jasoa: 10 maiatza, 2018; Onartua: 19 uztaila, 2018.

ISSN 0214-9001 - eISSN 2444-3255 / (c) 2019 UPV/EHU

cc)(-) () Obra hau Creative Commons Atribución 4.0 Internacional-en lizentziapean dago 


\section{SARRERA}

Azken aldian naturan gertatzen diren mekanismoak eta prozesuak imitatzen dituzten nanomaterialen garapena erronka nagusia bilakatu da hainbat arlotako zientzialarientzat. Biosistema hauen perfekzio eta eraginkortasun paregabeak ikertzaile askoren arreta erakarri du, eta sistema naturalen funtzioak imitatu ditzaketen material berrien diseinu eta garapena sustatu. ldo beretik, gaur egungo fotokimikan korronte arrakastatsueneritako bat fotosintesian bio-oinarritutako antena fotoniko artifizialen diseinuan eta garapenean oinarritzen da [1,2]. Landareetan aurkitzen diren organismo fotosintetikoak naturan eskuragarri dauden sistema aproposenak dira eguzki-energia xurgatu eta energia kimikoan eraldatzeko (1. irudia). Izan ere, biomasa sortzeko gai dira argiaren bidez aktibatutako erreakzio kimikoa dela medio. Eguzki-argia prozesuaren hasarazlea izanik, antena sistemak argiaren xurgapenaz arduratzen dira, non milaka klorofila-molekula inguru proteikoan antolatuta aurkitzen diren [3] (1c irudia).

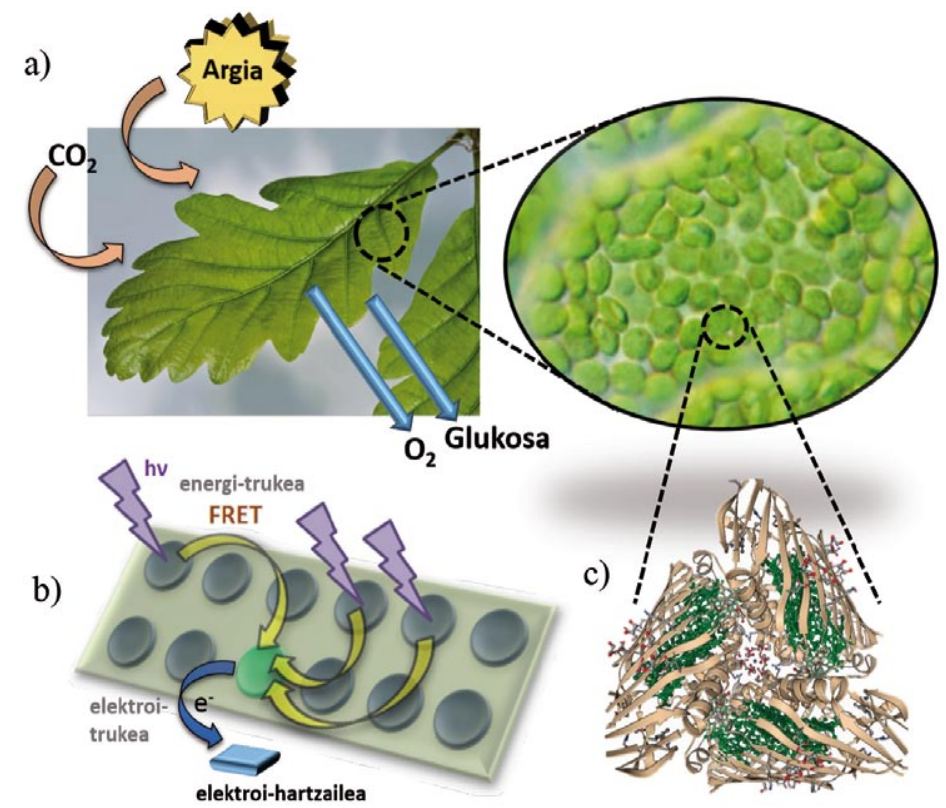

1. irudia. a) Fontosintesiaren prozesua adierazten duen eskema orokorra. Landare hostoak kloroplasto zelulez beterik daude, prozesu fotosintetikoa burutzearen arduradunak. Iturria: Botany 130. b) Antena efektuaren funtzionamendua deskribatzen duen eskema. Argia xurgatu eta ondoz-ondoko energia transferentzien bitartez energia hartzailearengana barreiatzen da, azkenik erreakzio gunean dagokion elektroi-trukea emateko. c) Sistema antena natural baten irudia, ehundaka klorofila molekula matrize proteiko baten barneratuta. Iturria: Laguna Design/Science Photo Library. 
Hainbat kromoforo naturalen antolaketa zehatzak eta hurbilak ultramore-ikusgai eremuko argiaren xurgapen eraginkorra ahalbidetzen du, eta ondoz ondoko energia eta elektroi- transferentziaren bitartez behar den erreakzio-gunera bideratzen da, argi-energia energia kimiko bilakatuz (1b irudia).

Gaur egun, ikerketa-esparru oso aktiboa da fotosintesiaren funtsezko prozesuen azterketa, eta era berean prozesu natural hauetan inspiratuz nanoteknologiaren garapena bultzatzea dispositibo berrien diseinua bermatzeko [4]. Antena-sistemen funtzionamendua aproposa izateko baldintza nagusietako bat argia modu eraginkorrean xurgatzea da, eta ondoren argi hori garraiatzeko ahalmena izatea ( $1 \mathrm{~b}$ irudia). Beraz, antena-sistema eraginkor baten garapenerako kontuan izan beharreko oinarrizko prozesuetako bat, energia- emaile eta energia-hartzaile bezala jokatzen duten molekulen arteko kitzikapen-energia (argi-energia) trukea (Excitation Energy Transfer, EET) deritzon fenomenoa da [5]. EET-a bermatuko duten molekula aproposak aukeratzerako orduan, ezinbestekoa da prozesuaren eraginkortasunaren gainean eragina duten zenbait parametroren ezagutza; hala nola, emaile eta hartzailea diren molekulen arteko kontzentrazio-erlazioa eta orientazioa, distantzia inter-kromoforikoa eta gainezarpen espektrala (hau da, emailearen fluoreszentzia-espektroa eta hartzailearen absortzio-espektroen artean). Aldagai hauen optimizazioaren bitartez, antena fotoaktiboen propietateak moldatu daitezke arlo ezberdinetan aplikatzeko, hala nola, fotonikan, biosentsoreetan, katalisian, gailu fotoboltaikoetan edo teragnosian biomedikuntzarako, besteak beste.

Azken urteotan, mota askotako saiakuntzak egin dira antena-propietatea duten material lumineszenteak eskuratzeko. Horretarako, sistema desberdinak frogatu dira; hala nola, dendrimeroak [6], konplexu metalikoak [7], koloratzailez dopaturiko polimeroak [8] edo material hibridoak [9]. Gure kasuan, azken sistema honetan oinarritu gara azken belaunaldiko antena material berri eta eraginkorragoak garatzeko. Ideia honi jarraituz, antena artifizialen konformaziorako L-zeolita aluminosilikatoaren nano-kanalak koloratzaile fluoreszenteen sorta batez dopatu dira. Koloratzaileek gune fotoaktibo bezala jokatuko dute (klorofilaren antzera) eta zeolita, berriz, euskarri solidoa izango da, sistema naturalen inguru proteikoa simulatuz [10].

Zeolitak hainbat egitura ezberdin (barrunbeak edo hodiak) izaten dituzten alumninosilikatoak dira. Ezagutzen diren zeolita natural eta sintetiko guztien artean, L-zeolita interesgarrienetako bat da; izan ere, kristalaren norabide luzeenean (c-ardatzean, 2 . irudian) zehar dimentsio bakarreko kanalak ditu [11]. Honez gain, $7.1 \AA$-tako diametrodun poroak (zilindrikoak) dauzka tamaina aproposeko koloratzaileak barneratzeko (2. irudia). Beraz, ingurune zeolitikoak koloratzailea babesten du kanpo-kalte ezberdinetatik (tenperatura zein eraso kimiko edota fotokimikoetatik), haren egonkortasuna handituz, eta, ingurunearen zurruntasuna dela medio koloratzaileek 
orientazio espezifiko bat hartzen dute. Honek molekulen antolaketa anisotropikoa ahalbidetzen du eta aldi berean haien arteko distantziak nabarmenki murrizten dira, emailearen eta hartzailearen arteko energia-trukea areagotuz [12-14]. Gogoan izan behar da azken prozesu hau funtsezkoa dela antena funtzioa ahalbidetzeko. Aurretiaz aipatu den bezala, energia-emaile eta -hartzailearen arteko distantziak eragin nabaria du EET-ren eraginkortasunean, honela, distantzia murrizterakoan energia trukea nabarmenki areagotzen da. Normalean, distantzia laburrak (1-100 $\AA$ ) bultzatzeko estrategia ezagun bat molekulen kontzentrazioa handiagotzea da. Gure kasuan, zeolitaren kanal estuek emandako konfinamenduak (poroen tamaina estuagatik) emaile-hartzaile bikoteen arteko distantzia izugarri murrizten dute, EET salto eraginkorrak ahalbidetuz, nahiz eta molekulen kontzentrazio baxuetan lan egin.

L-zeolita kristalak lortzeko, sintesi hidrotermala optimizatu da mikrouhinen beroketa erabiliz [15]. Protokolo honen bidez, kalitate handiko kristalak lor daitezke denbora laburrean (orduetan; beraz, energia eta dirua aurreztuz) eta horretaz gain, sintesiaren baldintzak doituz, tamaina (30-40 nm-tik 2-3 um-tara) eta morfologia (diskoak edo upelak) molda daitezke.
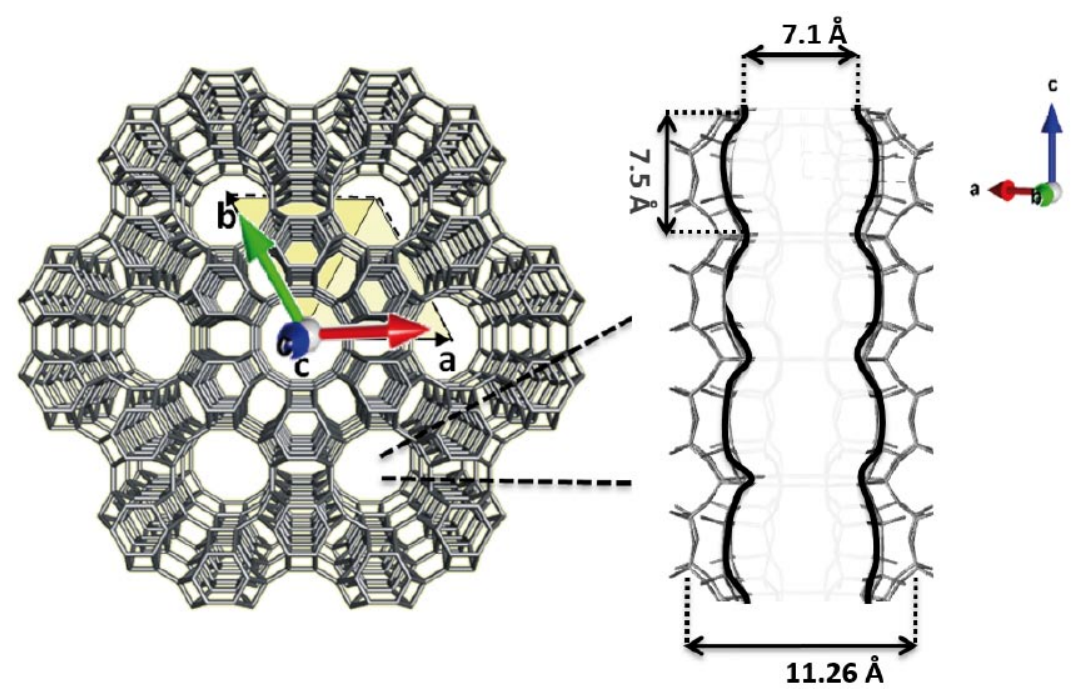

2. irudia. L zeolitaren egitura hexagonala goitik ikusita bere poro uni-dimentsionalekin batera. Kanal baten alboko bista $7.5 \AA$ A-ko dimentsiodun gelaxka unitatearekin, 7.1 ̊-ko van der Waals irekiera txikiena eta $11.26 \AA$ zabalenerako.

Behin euskarria aukeratuta, hurrengo pausua kanaletan barneratuko diren koloratzaileak hautatzea da, ultramore eta ikuskor eremuetako ahalik 
eta argi gehien biltzeko, eta energia- truke eraginkorrak bermatzeko. Beraz, fluoroforoak aukeratzerako orduan hurrengo faktoreak hartu behar dira kontuan: (i) tamaina poroen dimentsioekin bat etortzea estutasunez egokitzeko; (ii) absortzio- eta emisio-bandak ultramore-ikusgai osoan sakabanatuta izatea argiaren absortzioa tarte espektral zabal batean bermatzeko; eta (iii) energia-emailearen espektro fluoreszentea energia hartzailearen absortzio espektroarekin gainezartzea; horrela, hartzailea gai izango da emailearen kitzikapen energia xurgatzeko [10]. Gainjartze espektrala baldintza kritikoa da; izan ere, EET-ren mekanismoa espazioan zehar gertatzen den prozesua da, Förster-en teoriaren arabera (Förster Resonance Energy Transfer, FRET) [5].

Gaur egun, eta batez ere kimika organikoak emandako aurrerapausoei esker, molekula-egitura ugari aurkitu daitezke eskuragarri [16, 17]. Aurreko baldintzak kontuan hartuz, lan honetan ultramore-ikuskor eremuan aktiboak diren laser-koloratzaileen sorta bat aukeratu da L-zeolita dopatzeko: 1,4-bis-2-(4-methyl-5-phenyloxazolyl) benzene (DMPOPOP), Perileno Laranja (PL) eta Hostasol Gorria (HG) aukeratu ditugu emaile-hartzaile bikote bezala jokatzeko (3. irudia). DMPOPOP-a oxazol familiako koloratzaile bat da, ultramorean xurgatu eta ikusgaiko urdin-ertzean emititzen duena. Perileno Laranjaren banda espektralak ikusgaiko gune horian kokatuta daude eta, aldiz, Hostasol Gorriarenak gune gorrian aurkitu ditzakegu.

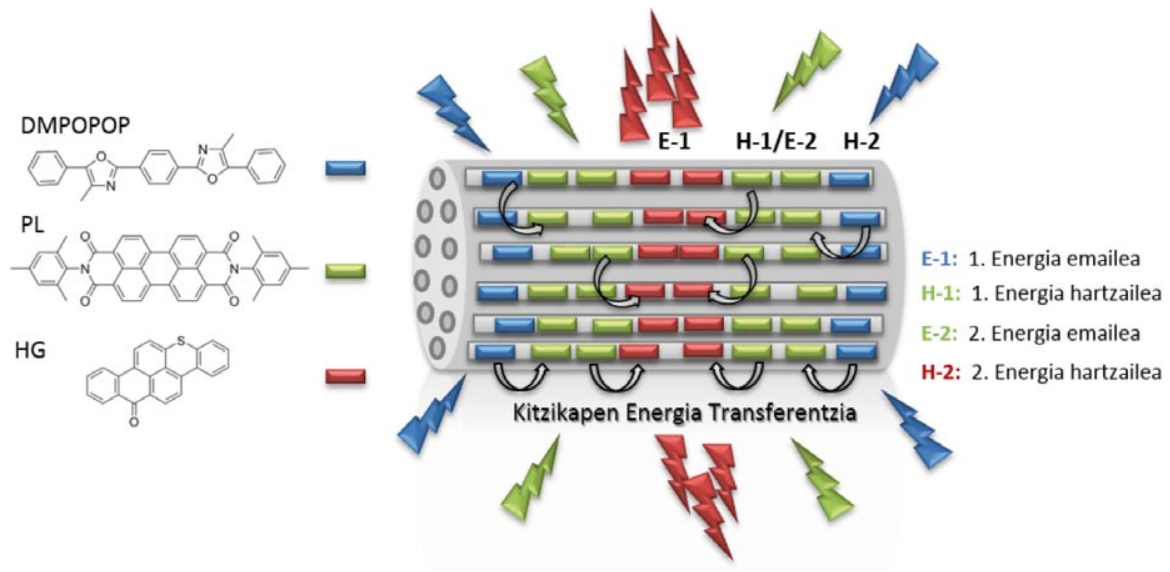

3. irudia. Antena-sistema fotoaktiboaren irudikapen eskematikoa koloratzaile ezberdinen egitura molekularrarekin batera. L-zeolitaren poroak espektro elektromagnetikoaren zonalde ezberdinetan absorbatzen eta igortzen duten koloratzaileez dopatu da, prozedura sekuentzial bati jarraituz. Energia ezberdineko argia xurgatu ostean, ondoz ondoko energia-transferentzien bitartez argi gorria igortzen duen gailua lortzen da. 
Lehendabizi, koloratzaile bakoitzaren ezaugarri fotofisikoen analisia burutu da disoluzioan, eta jarraian emaile-hartzaile bikoteen arteko energia-trukearen probabilitatean sakondu da. Behin aproposak direla estimatuta, L-zeolitan barneratu dira era sekuentzialean, hau da, bata bestearen atzean. Horretarako, azken energia-hartzailea (HG) sartu da lehendabizi, jarraian bere energia emailea (PL) eta amaieran, aurrekoaren atzean, dagokion energia-emailea (DMPOPOP) (3. irudia). Modu honetan, lorturiko material fotoaktiboa guztiz ordenatua eta fluoreszentea da, non HG kristalaren erdian kokatuta baitago, ondoan PL aurkitzen da albo banatan, eta azkenik DMPOPOP-a kristalaren ertzetan. Behin zeolita koloratzailez dopaturik dagoela, antenaren karakterizazio fotofisikoa burutu da egokia den ala ez jakiteko. Horretarako, argia ultramore-ikusgaian zehar xurgatu, eta ondoz ondoko energia- transferentzien bitartez emisioa nagusiki argi gorrian transformatzeko gai den balioztatu da. Bestalde, energiaren transferentzia oso eraginkorra ez den kasuetan, eremu ikusgaia estaltzen duten bandak (urdina, berdea eta gorria) ager daitezke. Kasu hauetan emisioa sintonizatzea posiblea da erabilera anitzeko material fotoaktiboen garapena ahalbidetuz.

\section{PROZEDURA ESPERIMENTALA}

\subsection{Koloratzaileak}

DMPOPOP eta Hostasol Gorria, GG Sigma-Aldrich eta Clariant saltzaileetatik eskuratu dira hurrenez hurren (3. irudia). Perileno Laranja Madrilgo Complutense Unibertsitatean sintetizatu da M. J. Ortiz irakaslearen eskutik. Egitura molekularraren diseinuaren helburua L-zeolitaren poroetan zehar difusioa erraztu eta interakzioa intermolekularrak sahiestea izan da (3. irudia) muturreko feniloen alkilazioaren bitartez (imidekin lotuta dagoena $\mathrm{N}$ atomoaren bidez). Abiapuntutzat, perileno dianhidridoa erabili da eta dagokion anilinarekin (trimetilatua) erreakzionarazi da, bi produktu hauek komertzialak izanik (Sigma-Aldrich).

\subsection{L-zeolitaren sintesia}

L-zeolita gure laborategian sintetizatu zen mikrouhinen bidezko sintesi hidrotermalaren bitartez [15]. Horretarako, alumina eta silikazko ur-suspentsioak nahasten dira eta sortutako gela kristalizaziorako egokia den tenperaturan berotzen da mikrouhinen labean.

Beroketa mota honek tenperatura gradienteak sahisten ditu, beroketa eraginkorragoa ziurtatuz eta erreakzio denborak nabarmenki murriztuz. 4. irudiko eskeman disko itxura duen L-zeolitaren mikrokristalak lortzeko baldintza zehatzak adierazten dira (lan honetan erabilitakoa antena luminiszenteak garatzeko). 
1. Alumina suspentsioa

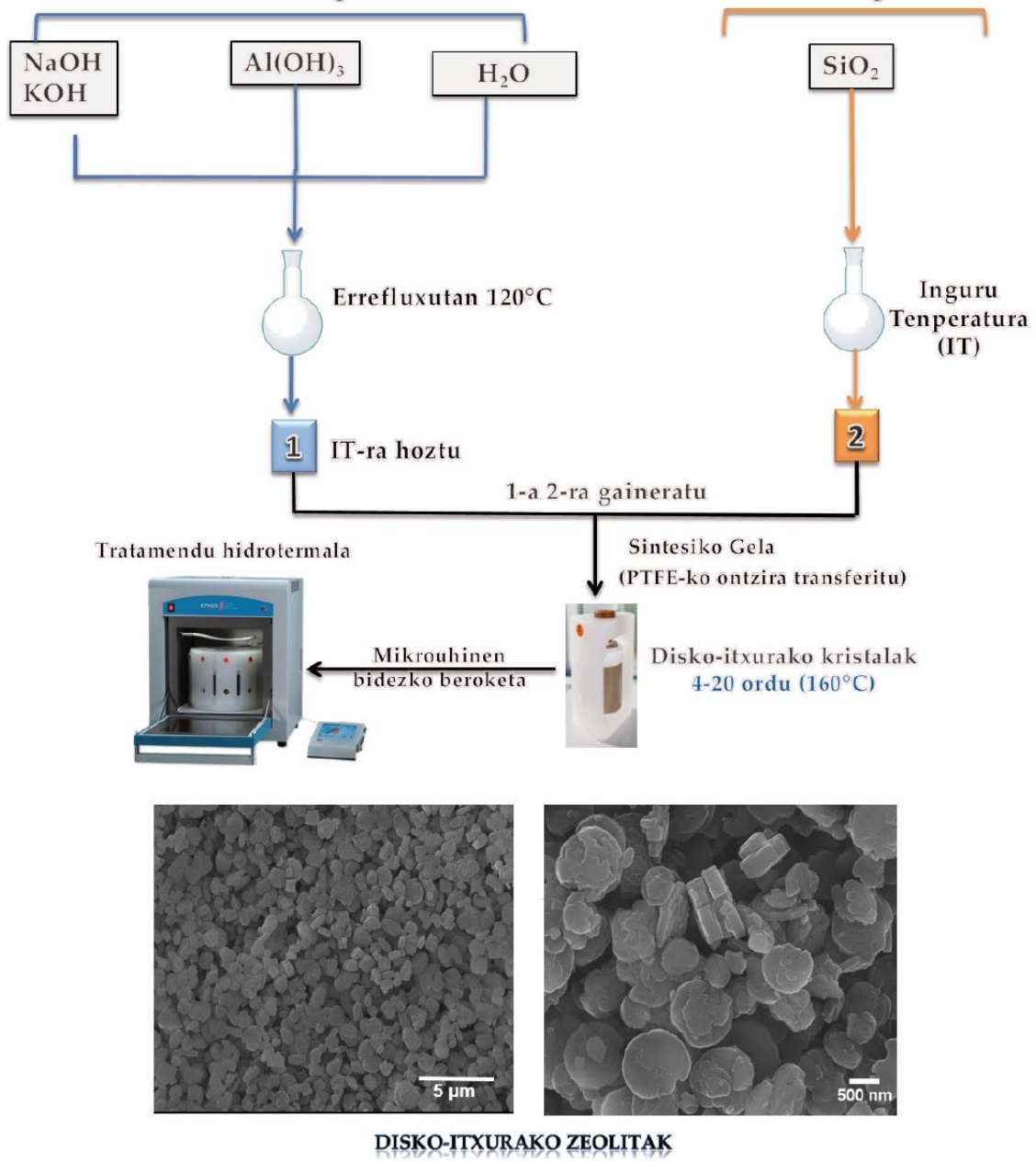

4. irudia. Disko itxurako L-zeolita lortzeko sintesi hidrotermala deskribatzen duen eskema lortutako kristalen mikroskopia elektronikoko irudiekin batera.

\subsection{Kanalen pH-aren egokitzapena}

Jarraian, koloratzailea sartu aurretik, lortutako L-zeolitaren kanalen pH-a egokitu da imidazol katioiarekin elkartrukatuz (Sigma Aldrich). Izan ere, protoien kontzentrazio handia dela eta, zeolitetako poroak azidotasun handia izatea du ezaugarri. Imidazol katioia protoiez ordezkatzerakoan azido-base orekak sahiesten dira eta koloratzaileen ezaugarri espektroskopikoak ez dira kaltetzen behin kanaletan barneratuta. 


\subsection{Koloratzaileen dopaketa eta kargaren estimazioa}

Koloratzaileen karga teorikoa kalkulatzeko bere dimentsio molekularrak eta okupatzen dituen gelaxka unitateak kontuan hartu dira. Horrela, koloratzaile bakoitzak okupatzen dituen adsortzio-gune kopuruaren estimazioa egiten da kasu bakoitzean, eta dagokion karga finkatzen da. Garatutako antenetan koloratzaileen kargak \%40-4 bitartekoak izan dira eta emaile/hartzaileen arteko erlazio ezberdinak probatu dira energi-trukean duten eragina aztertzeko. Behin imidazolarekin elkartrukaketa kationikoa eginda, koloratzaileen txertaketa tenperatura altuko adsortzioaren bitartez burutzen da hutsean. Fluoroforoen izaera neutroa izanik, hirurak sublimazio prozesuari esker L-zeolitaren poroetan barneratzen dira difusio prozesuaz lagunduta. Koloratzaile bakoitzarentzat barneratzetenperatura egokia optimizatu da: DMPOPOP-a eta $\mathrm{HG}-\mathrm{a} 200^{\circ} \mathrm{C}$-tan eta PL $250^{\circ} \mathrm{C}$-tan.

\subsection{Teknika instrumentalak}

Absortzio- eta igorpen-espektroak neurtzeko, ultramore-ikusgaiko absortzio (Varian Cary 4E modeloa) eta igorpen-fluoreszenteko (FLSP920 modeloko Edinburgh Instruments) espektrofotometroak erabili ziren, hurrenez hurren. Fluoreszentziaren etekin kuantikoak $(\phi)$ lortzeko, erreferentzia gisa koloratzaile komertzial egokiak erabili dira. Fluoreszentzia desaktibazio kurbak erregistratzeko aurreko erabilera anitzeko FLSP920 tresna erabili zen denborarekin korrelazionatutako fotoi-kontagailu kuantikoko teknikaren bidez (TC-SPC, Time-Correlated Single Photon Counting). Laginaren kitzikapena laser pultsatu (40 ps) eta sintonizagarrien bidez egin zen. Lortutako gainbehera kurba monoesponentzial bezala doitzen da, eta zuzenean maldaren inbertsoa eginez erdibizitza-denbora $(\tau)$ lortu zen. Doiketa ontzat emateko chi-square parametro estatistikoaren eta hondarren banaketa-analisian oinarritu ginen.

Disoluzio-eran zeuden laginen neurketarako, kuartzozko kubetak erabili ziren, kontzentrazio bakoitzerako bide optikoak egokituz $(1,0.1$ eta $0.01 \mathrm{~cm}$ disoluzioen $10^{-6}, 10^{-5}$ eta $10^{-4}$ M-ko kontzentrazioetarako hurrenez hurren). Lagin solidoen kasuan (koloratzailez dopatutako L-zeolita), hautsaren kantitate jakin bat diklorometanoan suspenditu zen $(1 \mathrm{mg} / 1 \mathrm{~mL}$ $\tan )$ eta beirazko porta batean $(20 \times 20 \mathrm{~mm})$ nahastearen $200 \mu \mathrm{L}$ xiringatu ziren dimentsio jakineko forma zirkularreko patroi batean. Jarraian lurruntzen utzi eta olio espektroskopikoaren tanta bat gehitu zitzaion lehorturiko solidoari eta beirazko bigarren porta batez estali zen, beira-hautsa-olioabeiraz osatutako sandwich-a lortuz. Konposite hau egokia da errefrakzioindizeen arteko aldea berdintzeko (airearen eta solidoaren artekoa); izan ere, zeoliten kristalek argia sakabanatzen dute eta horrek neurketa espektroskopikoak oztopa ditzake. 
Koloratzailez dopaturiko L-zeoliten fluoreszentziako irudiak koloredun CCD kamera batekin (DP72) ekipaturiko mikroskopio optikoaren bitartez erregistratu ziren epi-konfigurazioan (Olympus BX51). Laginen kitzikapena Chroma markako band-pass filtroen bidez burutu zen (350/50 and 470/40) eta emisioa cut-off filtroen bitartez (E400LPv2, igorpena $400 \mathrm{~nm}$-tik aurrera bilduz). Bestalde, kristalen tamaina eta morfologia-ekorketa mikroskopia elektronikoaren (SEM) bidez aztertu zen (JEOL JSM-7000F, Schottky FEG).

\section{EMAITZAK ETA EZTABAIDA}

\subsection{Koloratzailearen ezaugarri fotofisikoak}

Energia-emaile primariotzat 1,4-bis(5-phenyloxazol-2-yl) benzene dimetilatua (DMPOPOP) aukeratu da (3. irudia) [18]. Oxazolen familiako fluoroforo honek absortzio banda intentsua erakusten du ultramore-ikusgai mugan (1. taula eta 5. irudia). Banda hau kitzikatuz gero emisio urdin distiratsua behatzen da, nahiz eta molekularen egitura erlatiboki malgua izan (eraztunen arteko loturak biratu dezakete). Energia-hartzailetzat, berriz, Perileno Laranja (PL) eta Hostasol Gorria (HG) aukeratu dira (3. irudia). PL-ren nukleo kromoforikoa perileno bis-imidan oinarritzen da [19] (imidaren nitrogenoan metilatutako feniloak ditu) eta absortzio zabala eta intentsua erakusten du ikusgaiko eremu berdean (5. irudia). Banda arretaz aztertzerakoan, haren egitura bibrazionalari dagozkion sorbaldak bereiz daitezke, koloratzaile-familia honen propietate oso bereizgarria dena. Dagokion emisio-espektroa aldi berean, absortzio espektroaren ispilu irudia da, aipatutako egitura bibrazionala mantenduz. Kromoforo hau oso zurruna da, eta etekin kuantiko fluoreszente handia izatea du ezaugarri bereizgarri (1. taula). Beste alde batetik, HG kromoforoak dibenzo [a,h] pirenoarenaren antza du [20], baina karbono baten ordez tio funtzio taldea dauka eraztun batean (erdikoa) eta karbonilo ordezkatzailea beheko eraztunean (erdikoa), sistema konjokatua osatuz. Absortzio-bandaren posizioa perilenoaren antzekoa izan arren, haren emisioa tarte gorriraino desplazatzen da, eta ahalmen fluoreszente altua aurkezten du (5. irudia).

1. taula. Koloratzaileen propietate fotofisikoak diklorometanozko disoluzio diluituetan $\left(4 \cdot 10^{-6} \mathrm{M}\right)$ : absortzioa $\left(\lambda_{\mathrm{ab}}\right)$ eta fluoreszentzia $\left(\lambda_{\mathrm{fl}}\right)$ uhin-luzera maximoak, absortzio molar maximoa $\left(\varepsilon_{\max }\right)$, fluoreszentziaren etekin kuantikoa $(\Phi)$ eta erdibizitza denbora $(\tau)$.

\begin{tabular}{lccccc}
\hline & $\begin{array}{c}\lambda_{\mathrm{ab}} \\
(\mathrm{nm})\end{array}$ & $\begin{array}{c}\varepsilon_{\max } \\
\left(10^{4} \mathrm{M}^{-1} \mathrm{~cm}^{-1}\right)\end{array}$ & $\begin{array}{c}\lambda_{\mathrm{fl}} \\
(\mathrm{nm})\end{array}$ & $\Phi$ & $\begin{array}{c}\tau \\
(\mathrm{ns})\end{array}$ \\
\hline DMPOPOP & 366.5 & 3.7 & 431.0 & 0.90 & 1.44 \\
PL & 526.0 & 8.7 & 534.0 & 0.71 & 3.79 \\
HG & 511.5 & 1.9 & 583.0 & 0.72 & 9.35 \\
\hline
\end{tabular}



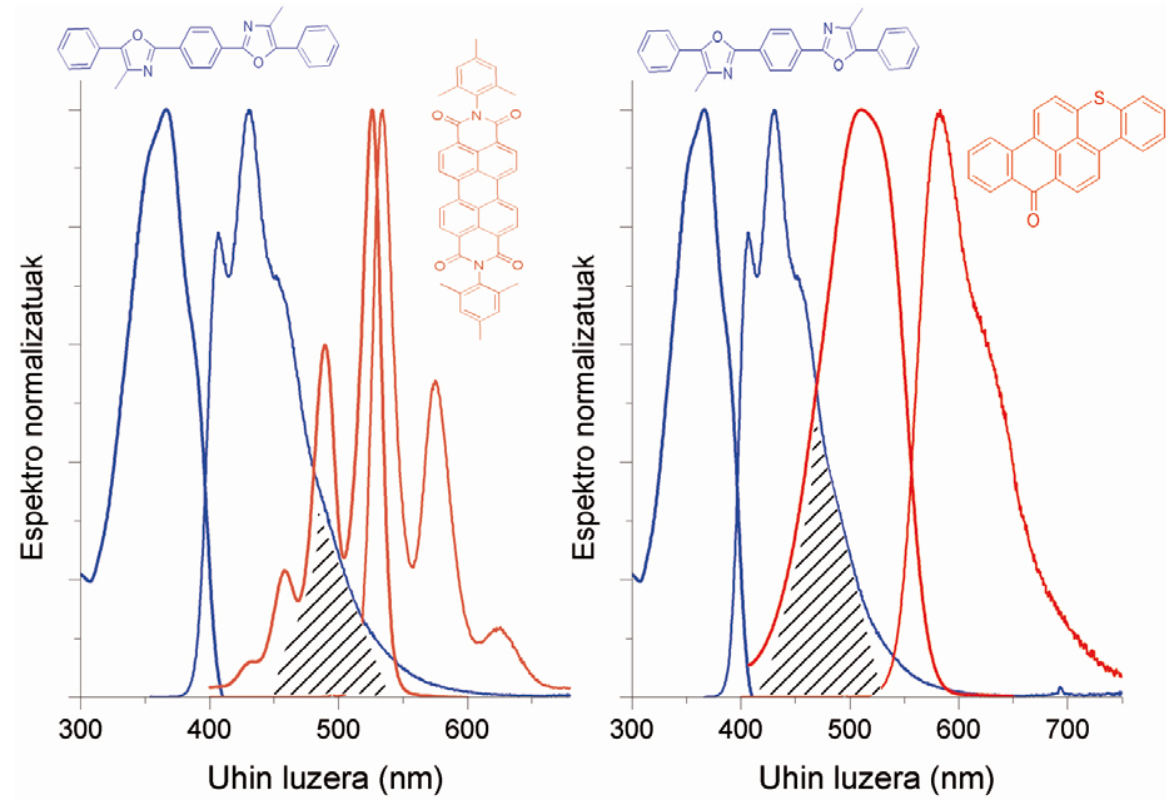

5. irudia. DMPOPOP-a, PL-a eta HG-ren absortzio (lerro lodia) eta fluoreszentzia (lerro fina) espektro normalizatuak diklorometanoan. Irudiak emaile-hartzaile bikoteen arabera antolatu dira (ezkerrean, DMPOPOP vs PL, eta eskuinean, DMPOPOP vs HG) eta marra beltzez gainjarpen espektrala adierazi da, emailearen emisioaren eta hartzailearen absortzioaren artean energia-trukea (FRET) ahalbidetzen duena.

Beraz, koloratzaile hauek aproposak dira aipatutako helburuak lortzeko; honako arrazoi hauengatik: i) argi sorta desberdina baina osagarria xurgatzen dute, ii) absortzio-ahalmen (absortzio molarraren bidez neurtzen dena, 1. taula) oso altua daukate, eguzki-erradiazio xurgapen eraginkorra ziurtatzeko ezinbesteko baldintza, iii) etekin kuantiko fluoreszentea $\% 70$ baino altuagoa da kasu guztietan (1. taula); beraz, igorritako argia distiratsua izango da, material fotoaktiboen betebeharrei erantzuna emanez.

\subsection{Energia Emaile-Hartzaileen nahasketak disoluzioan}

Aurreko baldintzez gain, lan honetan aurkezturiko koloratzaileak energia-trukea (FRET mekanismoaren bidez) berma dezaten hautatu dira. Prozesu honen balditzen artean ezinbestekoa da gainezarpen espektrala izatea emailearen emisioaren eta hartzailearen absortzioaren artean. Modu honetan, energia-trukerako beharrezkoa den mekanismo ez-erradiatzailea ahalbidetzen da. Fluoroforoen propietate fotofisikoak kontuan hartuz (5. irudia), bi bikote aukeratu dira FRET mekanismoaren bideragarritasuna 
egiaztatzeko; DMPOPOP-PL eta DMPOPO-HG. Horretarako, kontzentrazio ezberdineko nahasteak prestatu dira, betiere emaile/hartzaileen arteko erlazioa 1:1 mantenduz. Espero bezala, nahaste guztietan bi koloratzaileen presentzia detektatzen da absorbantzia espektroen arabera (6. irudia); uhin luzera baxuagoetan emailearena (DMPOPOP) eta altuagoetan hartzaileena (PL edo HG).
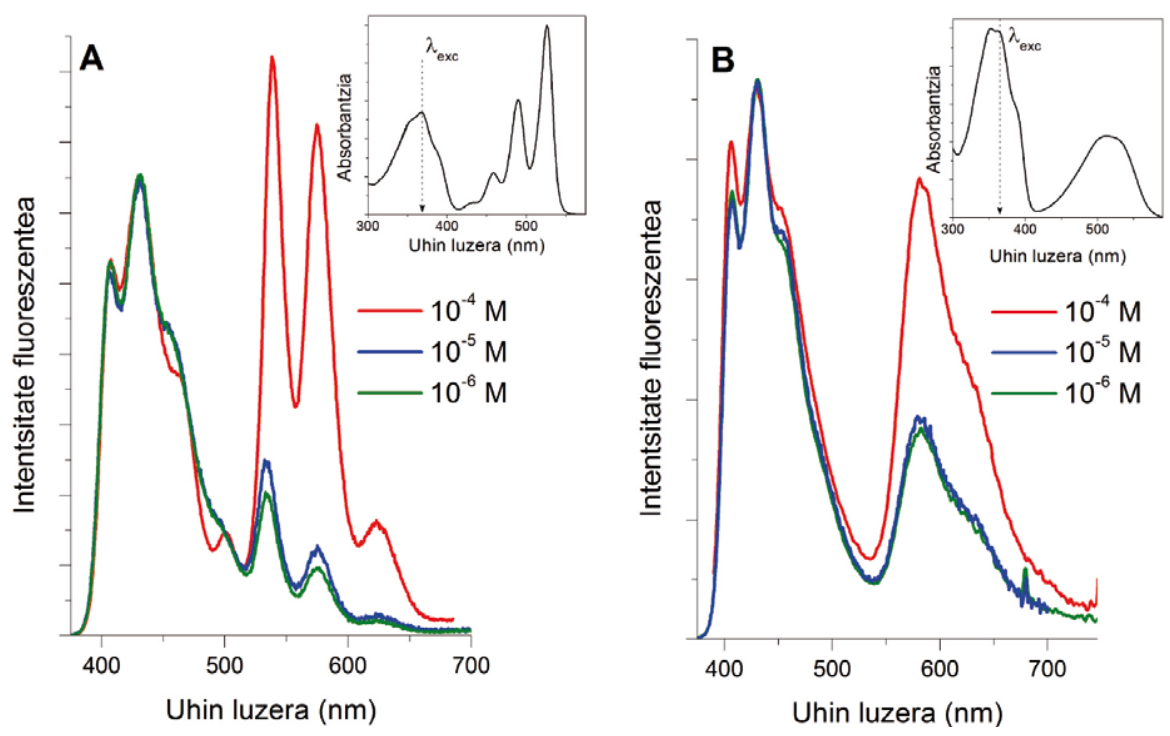

6. irudia. Koloratzaileen nahasteen (A: DMPOPOP-PL; B: DMPOPOP-HG) fluoreszentzia espektro normalizatuak (emailearen emisioan) diklorometanoan kontzentrazio ezberdinetan. Nahasteen absortzio espektroak (barruko grafikoak) ere erakusten dira kitzikapena $\left(\lambda_{\text {exc }}\right)$ emailearen absortzio-gunean gauzatu dela adierazteko.

FRET agerian jartzeko emailea selektiboki kitzikatu da, hau da, emisio-espektroa lortzeko finkatutako uhin-luzeran emaileak soilik xurgatzen du eta ez hartzaileak. Disoluzio diluituetan $\left(10^{-5}-10^{-6} \mathrm{M}\right)$ emailearen emisioa ikusten da batez ere, bi bikoteen kasuan hartzailearen seinalea oso ahula izanik (6. irudia). Hau logikoa da, izan ere disoluzio diluituetan emaile-hartzaileen arteko distantzia intermolekularra handia da eta ondorioz FRET probabilitatea baxua. Aldiz, kontzentrazioa handitzean $\left(10^{-4} \mathrm{M}\right)$ hartzailearen emisioa nabarmenki handiagotzen da, nahiz eta kitzikapeneko erradiazioa ez xurgatu, eta emailearen seinalea berdindu edo gainditu egiten du (6. irudia). Hortaz, kontzentrazioa handitzen den heinean distantzia intermolekularra murriztu egiten da, eta gainjarpen espektrala egokia denez, energia-trukearen probabilitatea handitu egiten da. 
Aipatzekoa da DMPOPOP-PL bikoteak energia-truke eraginkorragoa pairatzen duela hartzailearen emisioak, emailearena gainditzen baitu (DMOPOP-HG bikotean emailearen emisioa hartzailearen seinaleari nagusitzen zaio kontzentrazio handienean ere). Honen zergatia gainezarpen espektralean dago; lehengo bikotean handiago denez (5. irudia) FRET mekanismoa areagotu egiten da. Beraz, bikote hauen disoluzioak energia transferentzia pairatzeko aproposak direla frogaturik hautagai egokiak izan daitezke antena material berriak garatzeko.

\subsection{L-zeolita koloratzailez dopatuta}

Aukeratutako koloratzaileen artean energia-emaileen eta hartzaileen arteko energia-transferentzia bideragarria dela ziurtatu dugu disoluzioan zeuden nahasteetan. Beraz, hurrengo pausua molekula organiko horiek Lzeolitaren poroetan barneratzea izango litzateke, eta FRET mekanismoa ingurune zurrun honetan posiblea den egiaztatzea antena material hibridoak eskuratzeko. Horretarako, lehendabizi koloratzaile bakoitza bereizirik barneratu da L-zeolitaren poroetan. Koloratzaileak ondo barreiatzen dira kanaletan zehar eta koloredun hauts fluoreszenteak lortzen dira, fluoreszentziazko irudietan ikus daitekeen moduan (7. irudia).
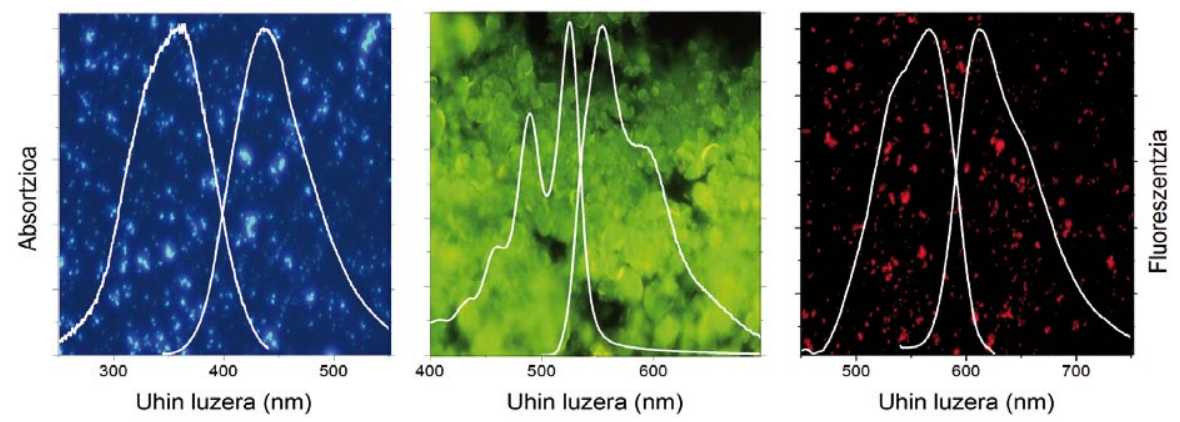

7. irudia. DMPOPOP (ezkerra), PL (erdian) eta HG-z (eskuina) dopatutako L-zeolitaren (bereizirik) absortzio eta fluoreszentzia espektroak normalizatuta. Atzealdeko argazkiak kasu bakoitzerako eskuratutako zeolita kristalen (koloratzaile bakoitzaz dopatuta) emisio irudiak dira fluoreszentziazko mikroskopiaren bidez erregistratuak.

Fluoroforoen ezaugarri espektroskopikoak zeolitan (7. irudia) eta disoluzioan (6. irudia) oso antzekoak dira. Beraz, sublimazio-prozesuaren ondoren koloratzaileen propietate fotofisikoak mantentzen direla ziurta daiteke kanaletako ingurune zurrun berrian. Agertzen diren aldaketa txikiak ingurunearen izaera desberdinera (zurruntasuna, polaritatea) eslei daitezke. Hori dela eta, aldez aurretik imidazolarekin egindako katioi-trukea ezin- 
bestekoa da azido-base orekak sahiesteko eta hauek eragindako aldaketa fotofisikoak saihesteko. Aipatzekoa da, nahiz eta zeolitaren poroetan koloratzaileen arteko distantziak oso txikiak izan, ez dela inongo interakzio intermolekularren aztarnarik behatu (adibidez, agregazioa). Beraz, koloratzaile bakoitzak bere ezaugarri fotofisikoak mantentzen dituela baiezta daiteke behin zeolita barruan egonda.

Bestalde, aipatzekoa da HG-ren kasuan banda espektralak lerrokatze batokromiko nabarmena jasaten dutela behin zeolitaren kanaletako ingurunean (8. irudia). Bibliografian portaera hau berresten duen joera argitaratu da, koloratzaile honen bandak gorrira desplazatzen direla ziurtatuz ingurune solido eta zurrunetan [21].

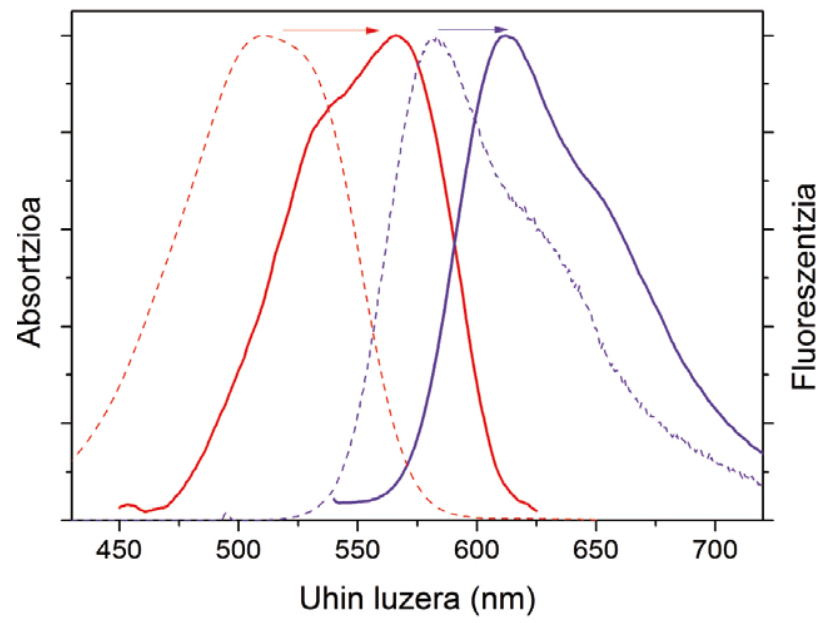

8. irudia. HG-ren absortzio (gorria) eta fluoreszentzia (morea) espektro normalizatutak zeolitan (lerro jarraia) eta disoluzioan (lerro etena).

Egoera berri honen aurrean, gure antenaren diseinua honela burutu da; lehendabizi azken energia hartzailea izango den HG-ren txertaketa egingo da (era berean argia igorriko duena); ondoren, jokabide bikoitza izango duen PL-a sartuko da, energia hartzaile eta aldi berean emaile bezala jokatuko duena, eta azkenik energia-emaile nagusia den DMPOPOP-a gehituko da (3. irudia). L-zeolitaren poro estuek koloratzaileen antolaketa sekuentziala bermatzen dute. Kanalen zurruntasuna dela medio, molekulen nahasketa sahiesten da, aurreko ordena eta antolaketa mantenduz, hau da, DMPOPOP-a ertzetan, HG-a erdian eta PL-a bien artean (3. irudia).

Hala ere, hiru koloratzaileez osatutako antena sortu aurretik, lehenik eta behin PL-a eta HG-a bikote aproposa zela egiaztatu nahi izan genuen ener- 
gia-truke eraginkorra jasateko. Horretarako, bi koloratzaile hauek zeolitan barneratu ziren bata bestearen atzean eta emisio espektroa neurtu zen kitzikapena HG-ak ia absorbatzen ez duen uhin-luzeran finkatuz, hau da, bereziki PL-a kitzikatuz. Lortutako espektroan, PL-ren emisioarekin batera, HG-ren fluoreszentzia gorria detektatu zen. Emaitza honek bi koloratzaileen arteko energi-trukea bidezkoa dela egiaztatzen du, hau da, PL energiaemailea aproposa dela HG energia hartzailerako.

Aurreko bikotea ondo zebilela ziurtatu ostean, antena artifiziala osatzeko azken osagaia barneratu zen, DMPOPOP-a. Guztira 3 antena sistema diseinatu dira, zeinetan PL-ren karga aldatu den (\%17, 30 eta 40 hurrenez hurren) beste bi koloratzaileena konstante mantenduz, DMPOPOP-a \%30-ean eta HG-a \%4-ean. 2. taulan antena-sistemen ezaugarri nagusiak laburbiltzen dira, hala nola koloratzaile bakoitzaren karga eta emaile/hartzaileen arteko erlazioak. Kasu guztietan absortzio espektroak neurtzerakoan hiru banda bereizgarri behatzen dira, koloratzaile bakoitzaren presentzia berretsiz; eremu urdinean DMPOPOP-a, berde-horian PL-a eta gorrian HG-a. Beraz, koloratzaileak poroetan zehar modu eraginkorrean barreiatzen direla esan daiteke, beren ezaugarri espektroskopikoak mantenduz. Ondorioz, sistema hibrido hauek argia xurgatzeko erakusten duten abilezia ezin hobea dela esan daiteke; ahaltsua, banda bakoitzaren absortzio molarrak altuak direlako, eta zabala, banda horiek ultramore-ikusgai eremu osoan zehar hedatzen direlako.

2. taula. Hiru antena-sistemak eraikitzeko erabilitako koloratzaileen kargak eta emaile/hartzaileen arteko erlazioak kasu bakoitzerako.

\begin{tabular}{ccccc}
\hline Antena sistemak & $\begin{array}{c}\text { DMPOPOP(E1) } \\
(\%)\end{array}$ & $\begin{array}{c}\text { PL (H1/E2) } \\
(\%)\end{array}$ & $\begin{array}{c}\text { HG (H2) } \\
(\%)\end{array}$ & E1:H1/EM2:H2 \\
\hline 1 & 30 & 17 & 4 & $7.5: 4.3: 1.0$ \\
2 & 30 & 30 & 4 & $7.5: 7.5: 1.0$ \\
3 & 30 & 41 & 4 & $7.5: 10.3: 1.0$ \\
\hline
\end{tabular}

Antena-izaera balioztatzeko emisio espektroak neurtu ziren ultramoreko gunean kitzikatuz, soilik DMPOPOP-ak xurgatzen duen zonaldean (9. irudia). Igorpen espektroa aztertzerakoan DMPOPOP-aren emisioa ez da ia antzematen (sorbalda bezala agertzen da gune urdinean) eta banda zabal bat eskuratzen da ikuskorreko tarte berde-gorrian zehar. Azken emisio hau PL-ren (uhin-luzera baxuetan, igorpen maximoa $\sim 550 \mathrm{~nm}$ inguruan) eta HG-ren emisioei (uhin-luzera handietan, $\sim 600 \mathrm{~nm}$ inguru eta nagusiena espektroan) dagozkie (9. irudia), hurrenez hurren. Beraz, energia-trukea DMPOPOP emailetik PL hartzailera oso eraginkorra da kasu guztietan, ia \%100. Izan ere emailearen emisioa oso ahula da kitzikapen energia har- 
tzailearengana transferitzen delako FRET mekanismoaren bitartez. PL-tik HG-ra gertatzen den energia-trukea, aldiz oso sentikorra da PL-ren kargaren arabera. Horrela, \%41ko kargaren kasuan PL-k jasaten duen FRET bidezko desaktibazioa ez da hain nabaria eta haren emisioa HG-arekin batera behatzen da (9. irudiko espektro berdea). Ostera, karga jaisten doan heinean energiaren transferentziaren areagotze nabarmena detektatzen da, \%17ko kargarekin HG-ren banda PL-arenari nagusituz (9. irudiko espektro gorria).

Emaitza hauek bat datoz CIE kromatizitate diagraman behatutakoarekin (9. irudia). PL-aren kargaren gutxiagotzearekin HG puruaren koordinatuetatik gero eta hurbilago gerturatzen da antenaren emisioa, hau da, fluoreszentziak geroz eta izaera gorriagoa azaltzen du, igorpen irudietan ikus daitekeen bezala (9. irudiko grafikoan txertaturiko irudietan). Energia-trukearen eraginkortasuna txikiena den kasuan kristalen emisioa laranja kolorekoa da, baina efizientzia handiagotzerakoan hauen igorpena kolore gorri distiratsuan bilakatzen da. Joera hau bibliografian bildutakoarekin bat dator; izan ere, antena-efektua eraginkorra izateko emaileen proportzioa hartzailearekiko handiagoa izateak energia-trukearen eraginkortasuna hobetzen du [22].
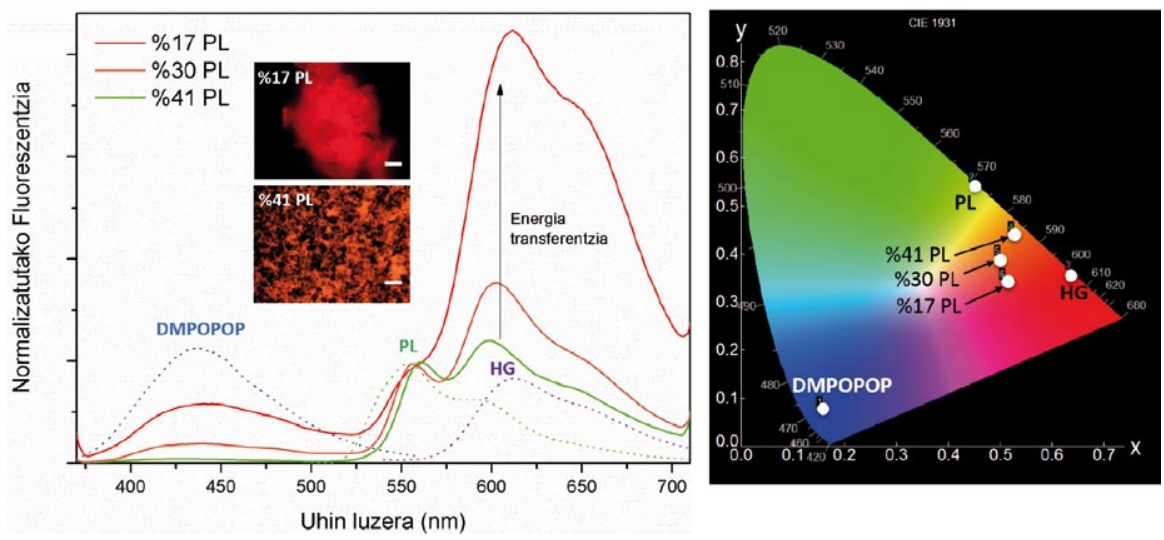

9. irudia. Ezkerrean: HG (\%4)-PL (\%17, 30, 41)-DMPOPOP (\%30) dopaturiko L-zeolita 3 laginen fluoreszentzia espektroa, eta emisio-irudia (barneko lerroak eskala adierazten du, $20 \mu \mathrm{m}$ ) $360 \mathrm{~nm}$-tan kitzikatuz (DMPOPOP-k soilik zurgatzen duen tartean). Koloratzaile bakoitzaren fluoreszentzia-espektroak zeolitan (lerro ez-jarraiak, DMPOPOP-a urdinez, PL-a berdez eta HG-a morez) gehitu dira alderatzeko. Eskuinean: Hiru antena-sistemen emisioren kokapena CIE 1931 kolore eremuaren diagraman; koloratzaile bakoitzaren igorpen datuak barneratu dira erreferentziatzat.

Kasu honetan, 2. taulako emaile/hartzaileen arteko proportzioak behatzerakoan zera ikusten da, efizientzia handiena aurkezten duen 1. antenaren 
kasuan emaile primarioa den DMPOPOP-etik hurrengo hartzaileekiko erlazioa gradualki jaitsiz doala (7.5 DMPOPOP: 4.3 PL: 1 HG), PL-ak bigarren emaile bezala jokatzen duela ahaztu barik. Beraz, honek HG-rekiko karga altuagoa izateak energia-transferentziaren eraginkortasuna areagotzea dakar. Aldiz, beste bi antenen kasuan PL-aren proportzioa DMPOPOP-aren berdina (2. antena) edo altuagoa denean (3. antena), energia transferentziak behera egiten du, goian ondorioztatutakoarekin bat etorriz.

Beraz, diseinatutako material fotoaktibo hauek azaltzen duten antena efektuaren bitartez, argia edozein ultramore-ikusgaiko gunetan xurgatuta ere, HG-ren emisio gorria berreskuratzen da ondoz-ondoko FRET sintonizagarriaren fenomenoari esker; hau da, DMPOPOP-tik PL-ra, eta hemendik HG-ra, azken honek argia igortzen duelarik. Gaur egun, erradiazio gorria oso erabilgarria da hainbat arlo (bio)teknologikotan aplikatzeko: telekomunikazioetan, zeren eta argi mota honek distantzia luzean bidaiatu baitezake interferentziarik gabe [23]; eguzki-zelulak aktibatzeko, erradiazio honen energia bat baitator erdieroaleen kondukzio- eta balentzia-banden arteko jauzi energetikoarekin [24]; biomedikuntzan, zeren eta argi gorria (leiho biologikoa, uhin-luzera $>650 \mathrm{~nm}$ ) sakonki barneratu baitaiteke ehunetan, detekzio prozesuetarako selektibitate eta sentikortasun handiagoak ahalbidetuz, esaterako, biorudian [25].

\section{ONDORIOAK}

L-zeolitaren nanokanalak koloratzaile egokiez dopatzea estrategia aproposa da hauen arteko energia-trukea areagotu eta fluoreszentzia desaktiba dezaketen agregazioa bezalako fenomenoak sahiesteko. Beraz, material hibrido hauek hautagai aproposak dira antena lumineszenteak garatzeko. DMPOPOP-a, Perileno Laranja eta Hostasol Gorria ondo barreiatzen dira dimentsio bakarreko poroetan zehar eta haren banda espektral intentsu eta bateragarriek argiaren xurgapen eraginkorra bermatzen dute ultramore-ikusgai eremuetan zehar. Gainera, L-zeolitak eskaintzen duen ingurune zurrunak koloratzaileak babesteaz gain, hauen orientazioa aproposa izatera behartu eta distribuzio ordenatua izan dadin ahalbidetzen du. Ondorioz, kristalen ertzetan xurgatzen den argi ultramorea (DMPOPOP molekulen bidez) energia-trukeari esker poroetan zehar garraiatu ahal da eta Perilenoaren bitartez kanalen erdialdean aurkitzen den Hostasol-arengana ailegatzen da. Konfinamenduak prozesu honen bideragarritasuna ziurtatzen du, ondoz ondoko energia salto eraginkorrak sustatzen baititu azken energia hartzailera iristeko. Beraz, antena-prozesuari esker, UM-ikuskorrean bildutako argi guztia Hostasol molekulek bereganatu dezakete energia-trukearen bidez eta azkenik haren emisio gorria eskuratu daiteke. 


\section{ESKER ONAK}

Artikulu hau Eusko Jaurlaritzak emandako diru-laguntzari (IT912-16 proiektua) eta Doktore-ondoko bekari (L. G.-R.) esker gauzatu da. Era berean, M. J. Ortiz irakasleari perilenoaren sintesiagatik eskerrak eman nahi dizkiogu.

\section{BIBLIOGRAFIA}

[1] BENNISTON, A.C., HARRIMAN, A. 2008. «Artificial Photosynthesis». Materials Today, 11, 26-34.

[2] EL-KHOULY, M.E., EL-MOHSNAWY, E., FUKUZUMI, S. 2017. «Solar energy conversion: from natural to artificial photosynthesis». J. Photochem. Photobiol. C, 31, 26-83.

[3] SCHOLES, G.D., FLEMING, G.R., OLAYA-CASTRO, A., VAN GRONDELLE, R. 2011. «Lessons from nature about solar light harvesting». Nat. Chem., 3, 763-774.

[4] HAMbOURGER, M., MOORE, G.F., KRAMER, D.M., GUST, D., MOORE, A.L., MOORE, T.A., 2009. «Biology and technology for photochemical fuel production». Chem. Soc. Rev., 38, 25-35.

[5] OLAYA-CASTRO, A., SCHOLES, G.D 2011. «Energy transfer from Förster-Dexter theory to quantum coherent light-harvesting». Int. Rev. Phys. Chem., 30, 49-77.

[6] NAKAMURA, Y., ARATANI, N., OSUKA, A. 2007. «Cyclic porphyrin arrays as artificial photosynthetic antenna: synthesis and excitation energy transfer». Chem. Soc. Rev., 36, 831-845.

[7] PUNTORIERO, F., SARTOREL, A., ORLANID, M., LA GANGA, G., SERRONI, S., BONCHIO, M., SCANDOLA, F. CAMPAGNA, S. 2011. «Photoinduced water oxidation using dendrimeric $\mathrm{Ru}$ (II) complexes a photosensitizers». Coord. Chem. Rev., 255, 2594-2601.

[8] FLEMING, C.N., JANG, P., MEYER, T.J., PAPANIKOLAS, J.M. 2004. «Energy migration dynamics in a $\mathrm{Ru}(\mathrm{II})$ - and $\mathrm{Os}(\mathrm{II})$-based antena polymer embedded in a disordered, rigid medium». J. Phys. Chem. B, 108, 22052209.

[9] CALZAFERRI, G. 2012. «Nanochannels: hosts for the supramolecular organization of molecules and complexes». Lagmuir, 28, 6216-6231.

[10] GARTZIA-RIVERO, L., BAÑUELOS, J. LÓPEZ-ARBELOA, I. 2015. «Excitation energy transfer in artificial antennas; from photoactive materials to molecular assemblies». Int. Rev. Phys. Chem., 34, 515-556.

[11] CALZAFERRI, G., HUBER, S., MAAS, H., MINKOWSKI, C. 2003. «Host-guest antenna materials». Angew. Chem. Int. Ed., 42, 3732-3758.

[12] OGAWA, M., KURODA, K. 1995. «Photofunctions of intercalation compounds». Chem. Rev., 95, 399-438. 
[13] RAMAMURTHY, V. 2000. «Controlling photochemical reactions via confinement zeolites». J. Photochem. Photobiol. C, 1, 14-166.

[14] SHULZ-EKLOFF, G., WÖHRLE D., VAN DUFFEL, B., SCHOONHEYDT, R.A. 2002. «Chromophores in porous silica and minerals: preparation and optical properties». Microporous and Mesoporous Materials, 51, 91-138.

[15] GARTZIA-RIVERO, L., BAÑUELOS, J., IZQUIERDO, U., BARRIO, V.L., BIZKARRA, K. CAMBRA, J.F., LÓPEZ-ARBELOA, I. 2014. «Microwave synthesis of LTL zeolites with tunable size and morphology: an optimal support for metal-catalyzed hydrogen production from biogas reforming processes». Part. Part. Syst. Charact., 31, 110-120.

[16] DSOUZA, R.N., PISCHEL, U., NAU, W.N. 2011. «Fluorescent dyes and their supramolecular host/guest complexes with macrocycles in aqueous solutions». Chem. Rev., 111, 7941-7980.

[17] DE MOLINER, F., KIELLAND, N., LAVILLA, R., VENDRELL, M. 2017. «Modern synthetic avenues for the preparation of functional fluorphores». Angew. Chem. Int. Ed., 56, 3758-3769.

[18] DOROSHENKO, A. O., PATSENKER, L. D., BAUMER ,V. N. et al. 1994. «Structure of sterically hindered aryl derivatives of fivemembered nitrogen containing heterocyclic ortho-analogs of POPOP,» Molecular Engineering, 3, 353-363.

[19] WEIL, T., VOSCH T., HOFKENS, J., PENEVA, K., MÜLLEN., K. 2010. «The Rylene Colorant Family - Tailored Nanoemitters for Photonics Research and Applications». Angew. Chem. Int. Ed.49, 9068-9072.

[20] DEVAUX, A. CALZAFERRI, G. MILETTO, I. CAO, P. BELSER, P. BRÜHWILER, D. KHOREV, O. HÄNER, R. and KUNZMANN, A. 2013. «Self-Absorption and Luminescence Quantum Yields of Dye-Zeolite L Composites». J. Phys. Chem. C. 117, 23034-23047.

[21] SUAREZ, S., DEVAUX, A., BAÑUELOS, J., BOSSART, O., KUNZMANN, A., CALZAFERRI, G. 2007. «Transparent zeolite-polymer hybrid materials with adaptable properties». Adv. Funct. Mater., 17, 2298-2306.

[22] DEL GUERZO, A. OLIVE, A. G. L., REICHWAGEN, J., HOPF, H. DESVERGNE, J.-P. 2005. «Energy Transfer in Self-Assembled [n]-Acene Fibers Involving $\geq 100$ Donors Per Acceptor». J. Am. Chem. Soc., 127, 1798417985.

[23] FAYED, T. A. 2009. «Extension of Fluorescence Response to the Near-IR Region». Reviews in Fluorescence. Ed: GEDDES, C. D. Springer.

[24] MAYERHÖFER, U., DEING, K., GRUB, K., BRAUNSCHWEIG, H., MEERHOLZ, K., WÜRTHNER, F. 2009. «Outstanding Short-Circuit Currents in BHJ Solar Cells Based on NIR-Absorbing Acceptor-Susbtituted Squaranines». Angew. Chem. Int. Ed., 48, 8776-8779.

[25] ABRAHAMSE, H., HAMBLIN, M. R. 2016. «New Photosensitizers for Photodynamic Therapy». Biochem. J., 473, 347-364. 